\title{
Late Recovery of Parathyroid Function After Total Thyroidectomy: A Case-Control Study
}

Authors

Juan José Díez ${ }^{1,2}$ (1) Emma Anda ${ }^{3}$, Julia Sastre ${ }^{4}$, Begoña Pérez Corral ${ }^{5}$, Cristina Álvarez-Escolá6, Laura Manjón7, Miguel Paja ${ }^{8}$, Marcel Sambo ${ }^{9}$, Piedad Santiago Fernández ${ }^{10}, 11$, Concepción Blanco Carrera ${ }^{12}$, Juan Carlos Galofré13, Elena Navarro ${ }^{14}$, Carles Zafón ${ }^{15}$, Eva Sanz ${ }^{15}$, Amelia Oleaga ${ }^{8}$, Orosia Bandrés ${ }^{16}$, Sergio Donnay ${ }^{17}$, Ana Megía ${ }^{18}$, María Picallo $^{9}$, Cecilia Sánchez Ragnarsson ${ }^{7}$, Gloria Baena-Nieto ${ }^{19}$, José Carlos Fernández-García ${ }^{20,21}$, Beatriz Lecumberri ${ }^{6}$, Manel Sahún de la Vega ${ }^{22}$, Ana R. Romero-Lluch ${ }^{14}$, Pedro Iglesias 1,2

\section{Affiliations}

1 Department of Endocrinology, Hospital Universitario Ramón y Cajal, Madrid, Spain

2 Department of Endocrinology, Hospital Universitario Puerta de Hierro Majadahonda, Instituto de Investigación Sanitaria Puerta de Hierro Segovia de Arana, Madrid, Spain

3 Department of Endocrinology, Complejo Hospitalario de Navarra, Pamplona, Spain

4 Department of Endocrinology, Complejo Hospitalario de Toledo, Toledo, Spain

5 Department of Endocrinology, Complejo Asistencial Universitario de León, León, Spain

6 Department of Endocrinology, Hospital Universitario La Paz, Madrid, Spain

7 Department of Endocrinology, Hospital Universitario Central de Asturias, Oviedo, Spain

8 Department of Endocrinology, Hospital Universitario de Basurto, Bilbao, Spain

9 Department of Endocrinology, Hospital Universitario Gregorio Marañón, Madrid, Spain

10 Department of Endocrinology, Complejo Hospitalario de Jaén, Jaén, Spain

11 Present address: Department of Endocrinology, Hospital Universitario Virgen de las Nieves, Granada, Spain

12 Department of Endocrinology, Hospital Universitario Príncipe de Asturias, Alcalá de Henares, Madrid, Spain

13 Department of Endocrinology, Clínica Universidad de Navarra, Pamplona, Spain

14 Department of Endocrinology, Hospital Universitario Virgen del Rocío, Sevilla, Spain

15 Department of Endocrinology, Hospital Universitario Vall d'Hebron, Barcelona, Spain

16 Department of Endocrinology, Hospital Royo Villanova, Zaragoza, Spain

17 Department of Endocrinology, Fundación Hospital de Alcorcón, Alcorcón, Madrid, Spain

18 Department of Endocrinology, Hospital Universitari de Tarragona Joan XXIII, IISPV, Universitat Rovira i Virgili, Ciberdem, Tarragona, Spain
19 Department of Endocrinology, Hospital de Jerez, Jerez de la Frontera, Cádiz, Spain

20 Department of Endocrinology, Hospital Universitario Virgen de la Victoria, Málaga, Spain

21 Department of Endocrinology, Hospital Regional Universitario de Málaga, Institute of Biomedical Research in Malaga (IBIMA), Malaga, Spain

22 Department of Endocrinology, Hospital Moisès Broggi, Sant Joan Despí, Barcelona, Spain

Key words permanent hypoparathyroidism, recovery of parathyroid function, calcium, calcitriol

received $\quad 10.02 .2021$

accepted after revision $\quad$ 15.08.2021

published online 13.09.2021

Bibliography

Horm Metab Res 2021; 53: 654-661

DOI 10.1055/a-1608-1373

ISSN 0018-5043

(C) 2021. Thieme. All rights reserved.

Georg Thieme Verlag, Rüdigerstraße 14,

70469 Stuttgart, Germany

Correspondence

Juan José Díez

Department of Endocrinology

Hospital Universitario Puerta de Hierro Majadahonda

Instituto de Investigación Sanitaria Puerta de Hierro Segovia

de Arana

Calle Manuel de Falla 1

28222 Majadahonda

Madrid

Spain

Tel.: + 34911917230

juanjose.diez@salud.madrid.org 


\section{ABSTRACT}

The clinical characteristics of patients with postoperative hypoparathyroidism who recover parathyroid function more than 12 months after surgery have not been studied. We aimed to evaluate whether the intensity of replacement therapy with calcium and calcitriol is related to the late recovery of parathyroid function. We compared the demographic, surgical, pathological, and analytical features of two groups of patients: cases, i. e., late recovery patients (those who recover parathyroid function $>1$ year after thyroidectomy, $n=40$ ), and controls, i. e., patients with permanent hypoparathyroidism $(n=260)$. Replacement therapy with calcium and calcitriol was evaluated at discharge of surgery, 3-6 months, 12 months, and last visit. No significant differences were found in clinical, surgical, pathological, or analytical characteristics between cases and controls. The proportion of cases who required treatment with calcium plus calcitriol at 12 months was significantly lower than that found in controls $(p<0.001)$. Furthermore, daily calcium and calcitriol doses in controls were significantly higher than those in cases at 3-6 months $(p=0.014$ and $p=0.004$, respectively) and at 12 months ( $p<0.001$ and $p=0.043$, respectively). In several models of logistic regression analysis therapy with calcium and calcitriol at 12 months was negatively related to late recovery of parathyroid function. Although delayed recuperation of parathyroid function after total thyroidectomy is uncommon (13\%), follow-up beyond 12 months is necessary in patients with postoperative hypoparathyroidism, especially in those whose needs of treatment with Ca and calcitriol are reducing over time.

\section{Introduction}

Total thyroidectomy is one of the most performed endocrine operations. Definitive or permanent postoperative hypoparathyroidism is the most common chronic complication of this procedure $[1,2]$. However, the time points used to determine when postoperative hypoparathyroidism should be classified as permanent have been a matter of debate among researchers in the last years $[3,4]$. Some authors consider that the 12 -month after thyroidectomy criterion should be used for this definition [5-9], while others advocate that postoperative hypoparathyroidism should be considered definitive if it lasts more than 6 months [10-14]. Recent international clinical guidelines seem to support this last criterion $[2,15,16]$, although some maintain the chronological criterion in 12 months [17].

Nevertheless, it has also been shown that the recovery of parathyroid function is a dynamic phenomenon and various authors have reported anecdotal cases or small groups of patients who recover thyroid function more than 6-12 months after thyroidectomy $[18,19]$. These late recovery patients have been barely studied given their low frequency.

Late recovery of parathyroid function might be related to the number of parathyroid glands inadvertently injured or removed during surgery and also to the ability of the glands remaining in situ to recover their function over time [20]. In turn, this recovery of parathyroid function could be influenced by the intensity of the replacement treatment used after surgery [21]. Therefore, our objective has been to assess whether the intensity of therapy with calcium (Ca) and calcitriol during the first year after thyroidectomy is related to late recovery of parathyroid function.

\section{Patients and Methods}

\section{Ethics approval and study design}

This study was carried out by members of the Thyroid Task Force of the Spanish Society of Endocrinology (SEEN), after receiving the approval of the board of directors of the SEEN and the ethical committee of the Hospital Universitario Ramón y Cajal (Madrid). All the details on the patients and methodology used are described in detail in a previous report [8]. Briefly, each researcher recruited all patients with total thyroidectomy who attended their outpatient clinic between January 1 and March 31, 2018. Inclusion criteria were: age $>14$ years at the time of thyroidectomy, availability of surgical and pathological reports, and follow-up in the same hospital for at least one year after thyroidectomy.

In every patient demographic data, details on surgical procedure, histopathological data, analytical data on Ca metabolism, and information on therapy with Ca and calcitriol were retrospectively collected. As this was a retrospective study, there was no prior programming of the frequency of visits or blood samplings. Each hospital acted according to its local protocols. All investigators retrieved clinical information at various stages, that is, at discharge from hospital after surgery, 3-6 months after surgery, 12 months after the surgery, and at last visit. Postoperative serum concentrations of $\mathrm{Ca}$ and parathyroid hormone (PTH) were defined as the values obtained within the first 48 hours after surgery. For the purpose of this study hypoparathyroidism at discharge was defined as the presence, in the immediate postoperative period, of serum Ca levels $<8.5 \mathrm{mg} / \mathrm{dl}$ with inappropriate low PTH levels $(<15 \mathrm{pg} / \mathrm{ml})$, and/or need for treatment with Ca or calcitriol at discharge from surgery $[2,17]$. We defined hypoparathyroidism at 12 months and definitive hypoparathyroidism as the need for treatment with Ca or calcitriol at 12 months after surgery or at the last visit of the follow-up, respectively. In this study, we considered three intensities of treatment for hypoparathyroidism, that is, oral Ca, calcitriol, and Ca plus calcitriol, the last modality being considered as high intensity therapy. Recovery of parathyroid function was defined from a clinical point of view, that is, as the absence of the need for treatment with $\mathrm{Ca}$ and/or calcitriol.

\section{Patients}

Three hundred subjects out of 1792 who underwent total thyroidectomy remained hypoparathyroid at 12 months after surgery. Of these, 40 patients $(13.3 \%)$ recovered parathyroid function throughout the subsequent follow-up until the last visit and were considered cases. The 260 remaining subjects with permanent hypoparathyroidism were considered as controls. 


\section{Statistical analysis}

For quantitative variables, results are expressed as mean \pm SD for normally distributed data and as median (interquartile range, IQR) for nonparametric data. Adjustment to normal distribution was tested by the Kolmogorov test. Categorical variables are described as ratios or percentages. For comparisons of means between two groups of patients, the Student's $t$-test was used for normally distributed data, and the Mann-Whitney U-test was used for nonparametric data. For ratio comparisons, the chi-square test or Fisher's exact test was used. Several models of logistic regression analysis were used to assess the late recovery of parathyroid function as a function of quantitative and qualitative variables. Since not all the variables were available in all the patients, we have indicated both in the text and tables, the sample size of each variable. All used tests were two-sided and differences were considered significant when $\mathrm{p}<0.05$.

\section{Results}

The group of late recovery patients consisted of 37 women and 3 men, aged $49.5 \pm 14.1$ years, and with a median follow-up of 60.5 (32.3-90.0) months. Demographic, surgical, pathological, and laboratory characteristics of these patients are shown in $>$ Table 1.
When we compared this group with patients with permanent hypoparathyroidism, no significant differences were found in any of the analyzed parameters. Although our study did not evaluate the time of functional recovery in each of the late recovery patients, data in $>$ Table 1 show that the time of follow-up was similar in cases and controls [60.5 (32.3-90.0) vs. 58 (28.5-109.5) months, $\mathrm{p}=0.590]$.

- Table 2 and $>$ Fig. 1 summarize the intensity of treatments used in the two groups throughout the study. At 12 months the proportion of patients requiring $\mathrm{Ca}$ and calcitriol was higher in patients with permanent hypoparathyroidism (71.2\%) compared to late recovery patients ( $37.5 \%$; $<0.001)$. In addition, patients with permanent hypoparathyroidism required doses of oral elemental Ca and calcitriol significantly higher than those in late recovery patients at $3-6$ months ( $p=0.014$ and $p=0.004$, respectively) and at 12 months after thyroidectomy $(p<0.001$ and $p=0.043$, respectively) ( $\triangleright$ Table 2 ).

We analyzed the proportions of subjects who required zero doses of $\mathrm{Ca}$ and calcitriol in the two groups. As can be seen in - Table 3, the proportion of late recovery patients who required zero-dose of calcitriol was found to be significantly higher than that found in patients with permanent hypoparathyroidism both at 3-6 months and at 12 months. We did not find significant differences

- Table 1 Demographic, surgical, pathological, and analytical features of the two groups of studied patients.

\begin{tabular}{|c|c|c|c|c|c|}
\hline & \multicolumn{2}{|c|}{$\begin{array}{l}\text { Late recovery patients } \\
(n=40)\end{array}$} & \multicolumn{2}{|c|}{$\begin{array}{l}\text { Patients with permanent hypoparathy- } \\
\text { roidism }(n=260)\end{array}$} & \multirow[t]{2}{*}{$\mathbf{p}$} \\
\hline & $\mathbf{n}$ & Value & $\mathbf{n}$ & Value & \\
\hline \multicolumn{6}{|l|}{ Demographic features } \\
\hline Gender (female) & 40 & $37(92.5)$ & 260 & $207(79.6)$ & 0.052 \\
\hline Age (years) & 40 & $49.5 \pm 14.1$ & 259 & $47.2 \pm 14.8$ & 0.366 \\
\hline Time of follow-up (months) & 40 & $60.5(32.3-90.0)$ & 260 & $58(28.5-109.5)$ & 0.590 \\
\hline \multicolumn{6}{|l|}{ Surgical features } \\
\hline Specialized surgical team & 40 & $35(90.0)$ & 260 & $198(76.2)$ & 0.063 \\
\hline Lymph node dissection & 40 & $15(37.5)$ & 260 & $134(51.5)$ & 0.126 \\
\hline 2-stage thyroidectomy & 40 & $2(5.0)$ & 260 & $26(10.0)$ & 0.396 \\
\hline Surgical complications & 40 & $3(7.5)$ & 260 & $34(13.1)$ & 0.441 \\
\hline Identification of parathyroid glands & 40 & $30(75.0)$ & 260 & $170(65.4)$ & 0.281 \\
\hline Autotransplantation & 40 & $4(10.0)$ & 260 & $26(10.0)$ & 1.000 \\
\hline \multicolumn{6}{|l|}{ Pathological features } \\
\hline Parathyroid tissue at histology & 39 & $11(28.2)$ & 259 & $87(33.5)$ & 0.586 \\
\hline Thyroid cancer & 40 & $33(82.5)$ & 260 & $190(73.1)$ & 0.246 \\
\hline \multicolumn{6}{|l|}{ Analytical features } \\
\hline Preoperative Ca (mg/dl) & 28 & $9.42 \pm 0.53$ & 149 & $9.47 \pm 0.58$ & 0.717 \\
\hline Postoperative Ca (mg/dl) & 30 & $7.73 \pm 0.81$ & 188 & $7.59 \pm 0.72$ & 0.376 \\
\hline Postoperative PTH (pg/ml) & 14 & $4.9(2.5-33.6)$ & 129 & $6.1(3.0-10.5)$ & 0.643 \\
\hline Undetectable PTH & 14 & $1(7.1)$ & 129 & $10(7.8)$ & 1.000 \\
\hline
\end{tabular}

Data are the number of patients (percentage), mean \pm SD for normally distributed data and median (interquartile range) for nonparametric data. Ca: Calcium; PTH: Parathyroid hormone. 
- Table 2 Distribution of the treatment modalities used for hypoparathyroidism throughout the study period in the groups of studied patients.

\begin{tabular}{|c|c|c|c|c|c|}
\hline & \multicolumn{2}{|c|}{$\begin{array}{l}\text { Late recovery patients } \\
(n=40)\end{array}$} & \multicolumn{2}{|c|}{$\begin{array}{l}\text { Patients with permanent hypoparathyroidism } \\
(n=260)\end{array}$} & \multirow[b]{2}{*}{$\mathbf{p}^{*}$} \\
\hline & $\mathbf{n}$ & Value & $\mathbf{n}$ & Value & \\
\hline \multicolumn{6}{|l|}{ At discharge } \\
\hline Treatment & 40 & & 260 & & 0.290 \\
\hline Oral Ca & & $7(17.5)$ & & $53(20.4)$ & \\
\hline Calcitriol & & $1(2.5)$ & & $1(0.4)$ & \\
\hline Ca and calcitriol & & $32(80.0)$ & & $206(79.2)$ & \\
\hline Dose of oral Ca (g/day) & 36 & $3.0(2.0-3.0)$ & 246 & $3.0(2.0-3.0)$ & 0.479 \\
\hline Dose of calcitriol ( $\mu \mathrm{g} /$ day) & 33 & $0.50(0.25-0.50)$ & 196 & $0.50(0.50-1.75)$ & 0.063 \\
\hline \multicolumn{6}{|l|}{ At 3-6 months } \\
\hline Treatment & 40 & & 260 & & 0.093 \\
\hline Oral Ca & & $13(32.5)$ & & $49(18.8)$ & \\
\hline Calcitriol & & $3(7.5)$ & & $13(5.0)$ & \\
\hline Ca and calcitriol & & $24(60.0)$ & & $198(76.2)$ & \\
\hline Dose of oral Ca (g/day) & 34 & $1.5(1.0-2.5)$ & 231 & $2.0(1.5-3.0)$ & 0.014 \\
\hline Dose of calcitriol ( $\mu \mathrm{g} /$ day) & 26 & $0.25(0.25-0.50)$ & 200 & $0.50(0.25-0.50)$ & 0.004 \\
\hline \multicolumn{6}{|l|}{ At 12 months } \\
\hline Treatment & 40 & & 260 & & $<0.001$ \\
\hline Oral Ca & & $18(45.0)$ & & $52(20.0)$ & \\
\hline Calcitriol & & $7(17.5)$ & & $23(8.8)$ & \\
\hline Ca and calcitriol & & $15(37.5)$ & & $185(71.2)$ & \\
\hline Dose of oral Ca (g/day) & 32 & $1.0(1.0-1.5)$ & 226 & $1.5(1.0-3.0)$ & $<0.001$ \\
\hline Dose of calcitriol (g/day) & 20 & $0.43(0.25-0.50)$ & 195 & $0.50(0.25-0.50)$ & 0.043 \\
\hline \multicolumn{6}{|l|}{ At last visit } \\
\hline Treatment & 40 & & 260 & & \\
\hline Oral Ca & & 0 & & $51(19.6)$ & \\
\hline Calcitriol & & 0 & & $28(10.8)$ & \\
\hline Ca and calcitriol & & 0 & & $181(69.6)$ & \\
\hline Dose of oral Ca (g/day) & & - & 225 & $1.5(1.0-2.5)$ & \\
\hline Dose of calcitriol (g/day) & & - & 204 & $0.50(0.25-0.50)$ & \\
\hline $\begin{array}{l}\text { Data are the number of pati } \\
\text { nonparametric data (doses } \\
\text { calculated only in patients } \\
\text { for each of these parameter } \\
\text { patients. }\end{array}$ & s indi & $\begin{array}{l}\text { variable that repre } \\
\text { calcitriol). The mec } \\
\text { on these values, e } \\
\text { mn headed by n. Ca }\end{array}$ & Stati & $\begin{array}{l}\text { edian (interquartile rar } \\
\text { f oral Ca and calcitriol I } \\
\text { es of Ca or calcitriol. Th } \\
\text { pared to the group of I }\end{array}$ & $\begin{array}{l}\text { for } \\
\text { sample size } \\
\text { recovery }\end{array}$ \\
\hline
\end{tabular}

between both groups of patients with regard to the percentages of patients requiring zero-dose of oral Ca ( $\triangleright$ Table 3 ).

Several models of logistic regression analysis were performed to study the dependence of the variable late recovery of parathyroid function as a function of several independent variables, including therapeutic, demographic, surgical, and pathological variables ( $\triangleright$ Table 4). Results showed that the need for high intensity therapy at 12 months (Ca and calcitriol) was negatively and significantly related to late recovery of parathyroid function both in the univariate analysis and in different multivariate models. We also found that late recovery was negatively associated to lymph node dissection $(p=0.015)$ and positively associated to the presence of thyroid cancer $(p=0.005)(\triangleright$ Table 4 , model 5$)$.

\section{Discussion}

This study was performed to characterize a group of 40 out of 300 patients (13.3\%) with hypoparathyroidism 12 months after thyroidectomy who were able to recuperate parathyroid function after this time, that is, that behaved as late recovery patients. Our data 
- Table 3 Proportion of subjects who required zero doses of oral calcium and calcitriol in the two groups.

\begin{tabular}{|c|c|c|c|c|}
\hline & \multicolumn{2}{|c|}{ Patients requiring zero-dose of oral Ca (\%) } & \multicolumn{2}{|c|}{ Patients requiring zero-dose of calcitriol (\%) } \\
\hline & $\begin{array}{l}\text { Late recovery patients } \\
(n=40)\end{array}$ & $\begin{array}{l}\text { Patients with permanent } \\
\text { hypoparathyroidism } \\
(\mathrm{n}=260)\end{array}$ & $\begin{array}{l}\text { Late recovery patients } \\
(n=40)\end{array}$ & $\begin{array}{l}\text { Patients with permanent } \\
\text { hypoparathyroidism } \\
(\mathrm{n}=260)\end{array}$ \\
\hline At discharge & 2.5 & 0.4 & 7.5 & 20.4 \\
\hline At 3-6 months & 7.5 & 5.0 & $32.5^{*}$ & 18.0 \\
\hline At 12 months & 17.5 & 8.8 & $45.0^{* *}$ & 20.0 \\
\hline
\end{tabular}

- Table 4 Results of five models of logistic regression to study the influence of high intensity therapy (Ca and calcitriol) at 12 months on the development of late recovery of parathyroid function.

\begin{tabular}{|c|c|c|c|c|c|c|}
\hline Model & $\begin{array}{l}\text { Independent variables included in } \\
\text { the model }\end{array}$ & $\mathbf{n}$ & $\begin{array}{l}\text { Significant variables in the } \\
\text { model }\end{array}$ & OR & $95 \% \mathrm{Cl}$ & $\mathbf{p}$ \\
\hline 1 & HIT 12 mo (univariate) & 300 & HIT 12 mo & 0.24 & $0.12-0.49$ & $<0.001$ \\
\hline 2 & HIT $12 \mathrm{mo}$ and therapeutic features & 300 & HIT 12 mo & 0.20 & $0.08-0.48$ & $<0.001$ \\
\hline 3 & $\begin{array}{l}\text { HIT } 12 \text { mo, therapeutic and } \\
\text { demographic features }\end{array}$ & 299 & HIT 12 mo & 0.21 & $0.09-0.52$ & 0.001 \\
\hline 4 & $\begin{array}{l}\text { HIT } 12 \text { mo, therapeutic, demograph- } \\
\text { ic and surgical features }\end{array}$ & 299 & HIT 12 mo & 0.24 & $0.10-0.59$ & 0.002 \\
\hline \multirow[t]{3}{*}{5} & $\begin{array}{l}\text { HIT } 12 \text { mo, therapeutic, demograph- } \\
\text { ic, surgical and pathological features }\end{array}$ & 297 & HIT 12 mo & 0.21 & $0.08-0.55$ & 0.002 \\
\hline & & & Lymph node dissection & 0.33 & $0.13-0.80$ & 0.015 \\
\hline & & & Thyroid cancer & 4.80 & $1.60-14.46$ & 0.005 \\
\hline
\end{tabular}

show that patients who recover parathyroid function after the first year of thyroidectomy did not receive more intensive treatment than patients who eventually develop definitive hypoparathyroidism. In fact, our patients in the late recovery group were treated with lower doses of both $\mathrm{Ca}$ and calcitriol, during the second semester after thyroidectomy. The percentage of patients requiring oral $\mathrm{Ca}$ and calcitriol treatment at 3-6 months and at 12 months was also lower in the late recovery group compared to the permanent hypoparathyroidism group.

To date, some studies have reported a few cases of late recovery of parathyroid function in postsurgical hypoparathyroidism, but we have not found any that define the demographic, surgical or clinical characteristics of these patients. The most extreme cases in terms of time elapsed since surgery were reported by Cusano et al. [22] in 4 patients who recover parathyroid function 8-16 years after surgery. This study was performed in 3 patients with parathyroid surgery and one patient with thyroidectomy for Graves' disease, and all of them in the context of treatment with exogenous
PTH(1-84). In patients undergoing total thyroidectomy for thyroid disease, Ritter et al. [18] reported that 9 out of 189 patients (4.8\%) with low PTH after thyroidectomy showed resolution of hypoparathyroidism between $6-12$ months. Of the 33 patients with hypoparathyroidism studied by Youngwirth et al. [23], 24 returned to normal parathyroid function within 1 week of surgery, and 3 $(9.1 \%)$ more at their last known follow-up (at least 1 year after intervention).

In an interesting study, Villarroya-Marquina et al. [7] analyzed 142 patients with protracted hypoparathyroidism, defined as hypoparathyroidism 1 month after surgery. Of them, $21(14.8 \%)$ recovered parathyroid function within $6-12$ months (intermediate recovery) and 12 (8.5\%) after 1-year follow-up (late recovery). In this relevant study the number of parathyroid glands remaining in situ (PGRIS), high-normal serum Ca at one-month, detectable PTH and cancer were clinical and metabolic variables influencing positively a late recovery. The study by Kim et al. [19] was conducted in 22 patients with definitive hypoparathyroidism, defined as serum 

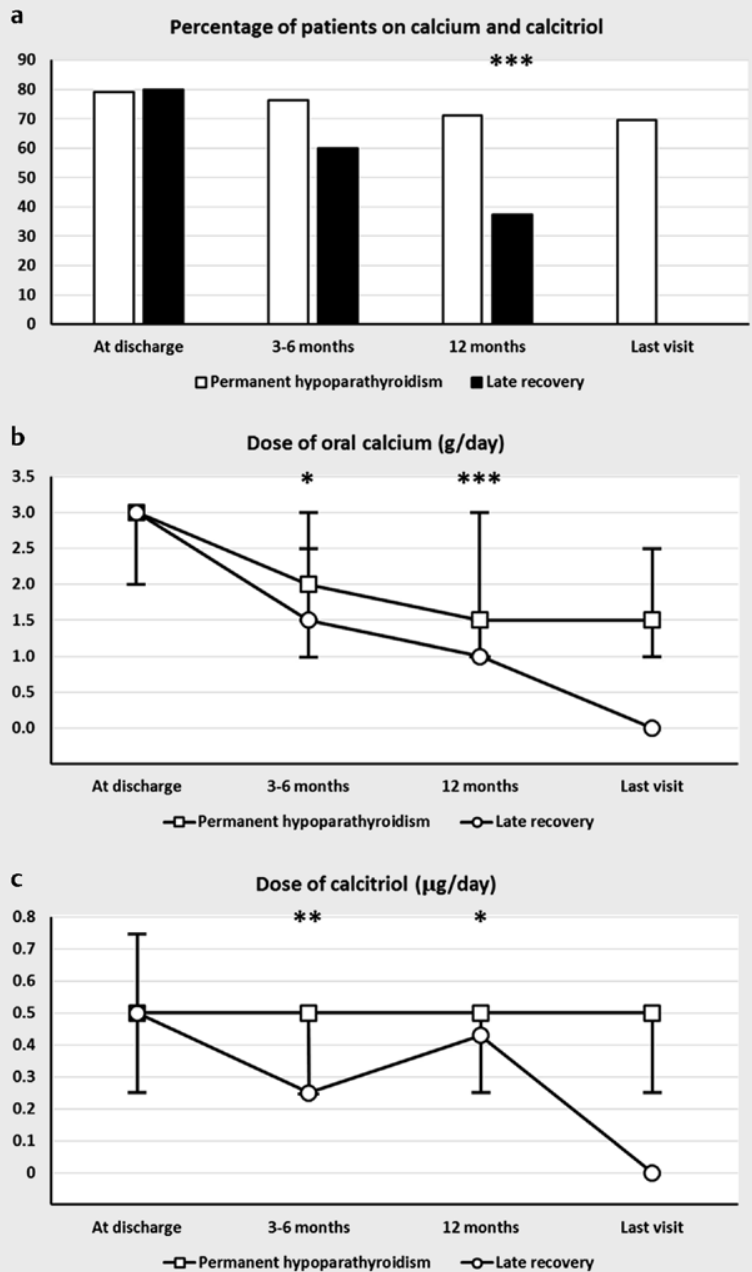

- Fig. 1 Intensity of therapy depicted by the percentage of patients who required oral calcium and calcitriol treatment (a) throughout the study (open rectangles, permanent hypoparathyroidism patients; black rectangles, late recovery patients), and by the dose of oral calcium (b) and calcitriol (c) throughout the study in the two groups of studied patients (squares, permanent hypoparathyroidism patients; circles, late recovery patients). Abscissa scale: time points in relation to thyroidectomy. Ordinate scale: Percentage of patients (a) and median of doses of oral calcium ( $\mathrm{g} /$ day) $(\mathbf{b})$ and calcitriol $(\mu \mathrm{g} /$ day) (c). In $\mathbf{b}$ and $\mathbf{c}$ median is the circle or the square. The bottom and top 'whiskers' are the lower (Q1) and upper (Q3) quartiles, respectively. ${ }^{*} \mathrm{p}<0.05 ;{ }^{*}{ }^{*} \mathrm{p}<0.01 ;{ }^{*}{ }^{*}{ }^{*} \mathrm{p}<0.001$ (permanent hypoparathyroidism patients vs. late recovery patients).

levels of PTH $<15 \mathrm{pg} / \mathrm{ml}$ for at least 1 year. Recovery from permanent hypoparathyroidism, defined as return to normal serum levels of PTH and Ca without exogenous supplementation, was observed in 5 patients ( $22.7 \%$, late recovery).

Possible mechanisms for the delayed recovery of parathyroid function have not been fully elucidated. It is reasonable to think that the slow but steady recovery of blood flow via neovascularization occurring over the surface area of the remaining parathyroid glands plays a major role. This is in direct relation to the number of PGRIS, a value that has been considered a predictor of parathyroid function recovery by some authors $[7,20]$. Despite we were unable to analyze the number of PGRIS in this study, we assessed the surgical identification of the parathyroid glands or the presence of parathyroid tissue in the specimen and none of them were related to late recovery of parathyroid function. In agreement with other authors $[20,21,24]$, parathyroid autotransplantation was not related to functional recovery.

The late recovery of parathyroid function could also be related to the pre- and postoperative PTH levels. It has been suggested that a better preoperative baseline parathyroid function, a higher absolute value of postoperative PTH and a lower drop in serum PTH in the immediate postoperative period would reflect less intraoperative parathyroid gland injury [6, 9, 11, 25]. Sitges-Serra et al. [26] showed that high-normal serum calcium and detectable PTH concentrations at 1 month after thyroidectomy were associated with better outcome of protracted hypoparathyroidism. A further study of the same group [7] suggested that serum Ca concentration at 1 month was associated with late recovery of parathyroid function, and that this was influenced by higher doses of $\mathrm{Ca}$ and calcitriol being prescribed at discharge.

The protective influence of high-normal Ca concentrations during the first weeks after surgery has been accounted for by a parathyroid splinting effect. According to this hypothesis, high-normal Ca levels would allow the injured, but viable, glands to rest, which would favor their long-term recovery [7]. If we apply this hypothesis to our patients, we would expect that those subjects who have received more intense treatment with $\mathrm{Ca}$ and calcitriol during the first year would have a greater probability of late recovery of parathyroid function. However, we obtained the opposite result; therefore, we think that this hypothesis, although applicable to early recovery, is not valid for late recovery. Besides, our study was only able to analyze $\mathrm{Ca}$ and PTH levels in a fraction of patients in the immediate postoperative period (24-48 h) and not in the first month or throughout the first year after surgery.

The most relevant finding of this study has therefore been the negative relationship between treatment intensification and recovery of parathyroid function. This association does not imply causality between treatment and recovery since our retrospective study cannot demonstrate any causal relationships. However, this finding allows us to speculate on the possibility that there is an association between the intensity of treatment and the physiological phenomena that lead to the functional reactivation of the synthesis and secretion of PTH. In fact, it is known that calcitriol exerts a negative regulation of parathyroid function [27, 28]. Based on this, it might be thought that high and sustained doses of calcitriol could somehow prevent or delay functional recovery. On the contrary, it could also be speculated that, in patients with lower intensity treatment, different episodes of hypocalcemia throughout the natural history of the disease would progressively stimulate the numb glands and bring on their final reactivation. Reduced supplement requirements might decrease the inhibitory action of $\mathrm{Ca}$ and vitamin D on parathyroid cells, resulting in increasing PTH secretion. In turn, PTH could exert trophic effects on parathyroid tissue, triggering pathways leading to enhanced vascularization as suggested by Cusano et al. [22].

Lymph node dissection was more often found in patients with permanent hypoparathyroidism versus patients with late recovery ( 51.5 vs. $37.5 \%$ ), but the proportion of patients with thyroid cancer were higher in the group of patients who recover parathyroid 
function (82.5 vs. 73.1\%). Although outside the scope of this study, these data suggest that lymph node dissection hinders functional recovery, probably related to greater parathyroid injury and difficulty in neovascularization in patients with lymphadenectomy, as reported by others $[7,19,20]$. Interestingly, the presence of cancer on histology is positively associated with late recovery, perhaps related to more careful surgical manipulation than in patients with benign disease [7]. In addition, these data are consistent with those obtained in the total cohort of 1792 patients previously reported in our initial study [8]. However, in this case-control study, none of these associations reached the level of statistical signification.

We believe that our results have relevance in the clinical care of patients undergoing treatment for chronic hypoparathyroidism. The diagnosis of this serious condition entails impact on the patient's quality of life, economic burden for the health system, and a lifelong medical follow-up with drug treatment and the possibility of adverse effects such as hypercalcemia and impaired kidney function [29, 30]. Our data suggest that in patients with low needs for replacement therapy with $\mathrm{Ca}$ and calcitriol, a trial of medication withdrawal can be performed with close monitoring of symptoms and laboratory values. In those who remain asymptomatic and normocalcemic, that is, late recovery patients, a lifetime medication that is not without adverse effects might be withdrawn.

The main limitation of this study is its retrospective nature. For this reason, we lack some variables that would have been of interest in our analysis (Ca and PTH concentrations in different follow-up times, number of PGRIS, vitamin D status). The doses of Ca and calcitriol were not available in all study subjects. We acknowledge that Ca and calcitriol treatment may not be more intensive therapy than calcitriol alone in some patients as the need for Ca replacement may be dependent in part on dietary Ca intake. However, this is a multicentric and nation-wide study with data from real clinical practice. The prevalence of definitive hypoparathyroidism in our cohort was higher than that reported in other studies. This may be due to the fact that this study was carried out in the setting of clinical practice of endocrinology clinics, where it is foreseeable that gather patients with greater complications and needs of follow-up after thyroidectomy. We must acknowledge that the possibility that the association of lower doses with the discontinuation of treatment is reverse causation, that is, patients with better residual parathyroid function and/or on the way to recovery need less medication. The main strength of the study lies in its sample size, since this is the first study including 40 patients with late recovery of parathyroid function, and, to our knowledge, it is the first survey dealing with the clinical characterization of patients who recover parathyroid function after one year after thyroidectomy and with the putative influence of replacement therapy in this late recovery process.

In few words, two theories have been raised to explain the relationship between replacement therapy, and the recovery of parathyroid function after an inadvertent injury during thyroidectomy. According to some authors, intensive treatment with $\mathrm{Ca}$ and calcitriol allows the parathyroid glands to be kept in a silent or numb state (splinting of the parathyroid glands), and this would favor functional recovery [7]. Other authors believe that it is convenient to maintain Ca values at the lower limit of the reference interval or slightly below this limit to avoid hypercalcemia and stimulate the parathyroid glands for the production of PTH and avoid its numbness [30,31]. Our data, although with limitations, due to the lack of serum levels of Ca and calcitriol throughout time in the studied patients, do not support the former and seem to favor the latter.

In conclusion, although most patients with hypoparathyroidism lasting more than 12 months will continue to require $C a$ and calcitriol supplements for life, there is a fraction of patients $(13.3 \%$ in our cohort) who were able to discontinue medical therapy after 12 months, especially in patients whose needs of treatment with $\mathrm{Ca}$ and calcitriol were reducing over time. This may reflect recovery of parathyroid function, although other possibilities exist. Further studies are needed to fully characterize these late recovery patients.

\section{Conflict of Interest}

The authors declare that they have no conflict of interest.

\section{References}

[1] Iglesias P, Diez J]. Endocrine complications of surgical treatment of thyroid cancer: an update. Exp Clin Endocrinol Diabetes 2017; 125: 497-505

[2] Orloff LA, Wiseman SM, Bernet V] et al. American thyroid association statement on postoperative hypoparathyroidism: Diagnosis, prevention, and management in adults. Thyroid 2018; 28: 830-841

[3] Harsløf T, Rolighed L, Rejnmark L. Huge variations in definition and reported incidence of postsurgical hypoparathyroidism: A systematic review. Endocrine 2019; 64: 176-183

[4] Bollerslev J, Schalin-Jantti C, Rejnmark L et al. Unmet therapeutic, educational and scientific needs in parathyroid disorders. Eur J Endocrinol 2019; 181: P1-P19

[5] Paek SH, Lee YM, Min SY et al. Risk factors of hypoparathyroidism following total thyroidectomy for thyroid cancer. World J Surg 2013; 37: 94-101

[6] Wang JB, Sun HL, Song CY et al. Association between decreased serum parathyroid hormone after total thyroidectomy and persistent hypoparathyroidism. Med Sci Monit 2015; 21: 1223-1231

[7] Villarroya-Marquina I, Sancho J, Lorente-Poch L et al. Time to parathyroid function recovery in patients with protracted hypoparathyroidism after total thyroidectomy. Eur J Endocrinol 2018; 178: $103-111$

[8] Diez J], Anda E, Sastre J et al. Prevalence and risk factors for hypoparathyroidism following total thyroidectomy in Spain: A multicentric and nation-wide retrospective analysis. Endocrine 2019; 66: 405-415

[9] Loncar I, Dulfer RR, Massolt ET et al. Postoperative parathyroid hormone levels as a predictor for persistent hypoparathyroidism. Eur J Endocrinol 2020; 183: 149-159

[10] Song CM, Jung JH, Ji YB et al. Relationship between hypoparathyroidism and the number of parathyroid glands preserved during thyroidectomy. World J Surg Oncol 2014; 12: 200

[11] Al-Dhahri SF, Mubasher M, Mufarji K et al. Factors predicting post-thyroidectomy hypoparathyroidism recovery. World J Surg 2014; 38: $2304-2310$

[12] Kim BW, Kim SY, Lee YS et al. Parathyroid score can predict the duration of required calcium supplementation after total thyroidectomy. PLoS One 2017; 12: e0174088 
[13] Filho EBY, Machry RV, Mesquita R et al. The timing of parathyroid hormone measurement defines the cut-off values to accurately predict postoperative hypocalcemia: A prospective study. Endocrine 2018; 61: 224-231

[14] Su A, Gong Y, Wu W et al. Does the number of parathyroid glands autotransplanted affect the incidence of hypoparathyroidism and recovery of parathyroid function? Surgery 2018 S0039$6060(17) 30928-5$

[15] Bollerslev J, Rejnmark L, Marcocci C et al. European society of endocrinology clinical guideline: treatment of chronic hypoparathyroidism in adults. Eur J Endocrinol 2015; 173: G1-G20

[16] Brandi ML, Bilezikian JP, Shoback D et al. Management of hypoparathyroidism: summary statement and guidelines. J Clin Endocrinol Metab 2016; 101: 2273-2283

[17] Stack BC Jr., Bimston DN, Bodenner DL et al. American association of clinical endocrinologists and American college of endocrinology disease state clinical review: postoperative hypoparathyroidism - definitions and management. Endocr Pract 2015; 21: 674-685

[18] Ritter K, Elfenbein D, Schneider DF et al. Hypoparathyroidism after total thyroidectomy: incidence and resolution. J Surg Res 2015; 197: 348-353

[19] Kim SM, Kim HK, Kim KJ et al. Recovery from permanent hypoparathyroidism after total thyroidectomy. Thyroid 2015; 25: 830-833

[20] Lorente-Poch L, Sancho J], Ruiz S et al. Importance of in situ preservation of parathyroid glands during total thyroidectomy. $\mathrm{Br}$ J Surg 2015; 102: 359-367

[21] Sitges-Serra A, Ruiz S, Girvent M et al. Outcome of protracted hypoparathyroidism after total thyroidectomy. Br J Surg 2010; 97 : 1687-1695
[22] Cusano NE, Anderson L, Rubin MR et al. Recovery of parathyroid hormone secretion and function in postoperative hypoparathyroidism: a case series. J Clin Endocrinol Metab 2013; 98: 4285-4290

[23] Youngwirth L, Benavidez J, Sippel R et al. Parathyroid hormone deficiency after total thyroidectomy: incidence and time. J Surg Res 2010; 163: 69-71

[24] Edafe O, Antakia R, Laskar N et al. Systematic review and meta-analysis of predictors of post-thyroidectomy hypocalcaemia. Br J Surg 2014; 101: $307-320$

[25] Almquist M, Hallgrimsson P, Nordenstrom E et al. Prediction of permanent hypoparathyroidism after total thyroidectomy. World ] Surg 2014; 38: 2613-2620

[26] Sitges-Serra A, Gomez ], Barczynski M eti al.. A nomogram to predict the likelihood of permanent hypoparathyroidism after total thyroidectomy based on delayed serum calcium and iPTH measurements. Gland Surg 2017; 6: S11-S19

[27] Cantley LK, Russell J, Lettieri D et al. 1,25-Dihydroxyvitamin D3 suppresses parathyroid hormone secretion from bovine parathyroid cells in tissue culture. Endocrinology 1985; 117: 2114-2119

[28] Ritter CS, Brown AJ. Suppression of PTH by the vitamin D analog eldecalcitol is modulated by its high affinity for the serum vitamin D-binding protein and resistance to metabolism. J Cell Biochem 2011; 112: 1348-1352

[29] Clarke BL. Epidemiology and complications of hypoparathyroidism. Endocrinol Metab Clin North Am 2018; 47: 771-782

[30] Bilezikian JP. Hypoparathyroidism. J Clin Endocrinol Metab 2020; 105: $1722-1736$

[31] Mannstadt M, Bilezikian JP, Thakker RV et al. Hypoparathyroidism. Nat Rev Dis Primers 2017; 3: 17055 